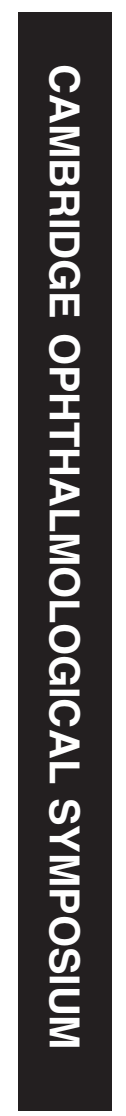

${ }^{1}$ Royal Victorian Eye and Ear Hospital, Centre for Eye Research Australia, University of Melbourne, Melbourne, Victoria,

Australia

${ }^{2}$ Centre for Eye Research Australia and Department of Surgery, University of Melbourne Royal Victorian Eye and Ear Hospital, Melbourne, Australia

Correspondence:

JG Crowston, Royal Victorian Eye and Ear Hospital, Centre for Eye Research Australia, University of Melbourne, 32 Gisborne Street, Melbourne VIC 3002 , Victoria, Australia Tel: +61 39929 8429; Fax: +61 399298794 . E-mail: Crowston@unimelb. edu.au

Received: 24 October 2016 Accepted: 30 October 2016 Published online:

6 January 2017

\section{Targeting retinal ganglion cell recovery}

\author{
Abstract \\ Accumulating evidence from experimental \\ and clinical studies suggest that retinal \\ ganglion cells at least in the earlier stages of \\ glaucoma have the capacity to recover \\ function following periods of functional loss. \\ The capacity for recovery may be negatively \\ impacted by advancing age but can be \\ boosted by interventions such as diet \\ restriction and exercise. \\ Eye (2017) 31, 196-198; doi:10.1038/eye.2016.281; \\ published online 6 January 2017
}

Vision loss in glaucoma results from the progressive loss of retinal ganglion cells (RGCs) and is generally considered irreversible. Accumulating data generated over recent decades, however, points to plasticity in the inner retina, with the potential for vision recovery in glaucoma patients in response to intraocular pressure (IOP) lowering. ${ }^{1}$ This manuscript will consider some of the clinic evidence for vision recovery in glaucoma and outline recent experimental data from our laboratory that have shed light on factors that impact the capacity for RGCs to recovery from IOP-mediated injury.

Early evidence for visual improvement in glaucomatous eyes has been largely derived from smaller cohort studies, which have documented improvement in various parameters of vision in response to IOP lowering. Gilian Paterson ${ }^{2}$ at Moorfields Eye Hospital provided one of the early examples of visual field improvement in glaucoma. She demonstrated reduction in scotoma, mapped by Goldman perimetry, in a cohort of open-angle glaucoma patients before and $30 \mathrm{~min}$ after the administration of intravenous acetazolamide. Although the level of improvement varied among individuals, visual field improvement was generally more apparent in younger patients and patients with earlier stages of disease. In a 1983 editorial, George Spaeth contended that: 'glaucoma cannot with certainty be considered controlled unless the IOP has been
JG Crowston¹, ET Fahy1, L Fry', IA Trounce1, $P$ van Wijngaarden ${ }^{1}$, S Petrou ${ }^{2}$ and $\checkmark$ Chrysostomou $^{1}$ lowered to a level associated with improvement in the disc or field'. ${ }^{3}$ Spaeth subsequently published evidence for visual field and optic nerve head improvement in a cohort of 75 openangle glaucoma patients in response to initiation of IOP-lowering medication. Reversal in opticdisc cupping was observed in $25 \%$ and visual field improvement in $31 \%$ of individuals. ${ }^{4}$

IOP lowering has been shown to improve other aspects of visual function. Gandolfi et $a l^{5}$ investigated spatial contrast sensitivity in a cohort of 10 open-angle patients with high preoperative IOP (30 $\mathrm{mm} \mathrm{Hg}$ or higher), but no visual field loss. A persistent increase in contrast was observed at 3, 6, and 12 cycles/degree, following substantial IOP lowering with trabeculectomy. Functional improvement in the inner retina has also been documented using retinal electrophysiology. Using the full-field electroretinogram (ERG), we demonstrated an increase in the photopic negative response (PhNR) amplitude in glaucomatous and ocular hypertensive eyes. ${ }^{6}$ Sehl et al, showed a significant improvement in the pattern ERG (PERG) in a cohort of 47 patients who underwent trabeculectomy or glaucoma drainage device surgery. A further study by Ventura and Porciatti ${ }^{1}$ examined retinal function in 25 glaucoma patients in response to topical glaucoma therapy. They demonstrated an improvement in PERG amplitude and/or phase beyond the $95 \%$ CI for test-retest variability in up to $56 \%$ of treated eyes. Eyes with more advanced glaucoma showed less capacity for improvement. A further important component of this study was the investigation of a control non-glaucoma cohort who underwent IOP lowering (with acetazolamide). Here, there was no change to the PERG indicating that PERG improvement is not a consequence of IOP lowering per se and may only manifest when RGC function is compromised. The visual evoked potential that is used to assess optic nerve function does not appear to improve with IOP lowering. ${ }^{8}$

IOP lowering is not the only approach to improving RGC function. Casson et al ${ }^{9}$ recently demonstrated that elevation of vitreous glucose levels in pseudophakic eyes with glaucoma also 
induced a significant improvement in contrast sensitivity. ${ }^{10}$ This is an interesting finding as it suggests that altering metabolic substrates can boost visual function. Further work is now required to determine in which cell population glucose-mediated neuroenhancement is occurring.

All of the above studies were based around short-term improvement in visual function and an outstanding question was whether this improvement could persist over a longer duration. This has been partially answered in a recent study by Caprioli et a ${ }^{11}$ who examined progression in individual visual field locations over time before and then up to 5 years after trabeculectomy. The investigators demonstrated a significant improvement in $>10$ visual field loci in $57 \%$ of eyes undergoing trabeculectomy and the magnitude of IOP lowering correlated with the number of improving field loci. ${ }^{11}$

In light of this accumulating clinical evidence, we became interested in examining parameters that might modify the capacity for RGCs to recover function and some of the underlying mechanisms. To this end, we have developed a model of recoverable RGC function in the mouse eye, where one eye of an anesthetized mouse is subject to a single IOP challenge of $50 \mathrm{~mm} \mathrm{Hg}$ lasting 30 min. ${ }^{12,13}$ Retinal function is monitored before, and at 7 and 28 days post injury using the full-field ERG. We are able to monitor inner retinal (largely RGC) function by measuring the PhNR component of the ERG in lightadapted eyes or the positive scotopic threshold response in dark-adapted eyes. An early discovery was that mouse age had a major impact on the rate of functional recovery. Whereas young 3-month-old animals recover full inner retinal function by 7 days post injury, functional recovery

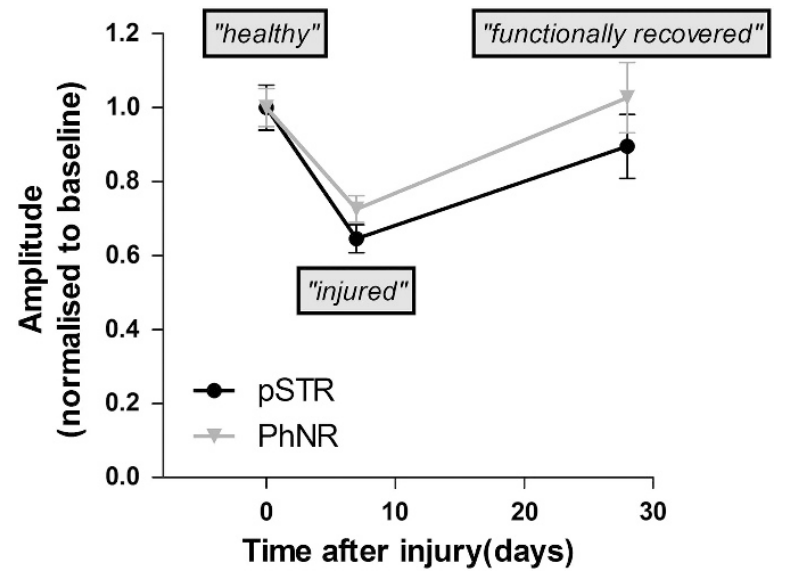

Figure 1 Shows functional recovery of the inner retina over time in two cohorts of 12-month-old C57BL/ 6 mice. Inner retinal function (largely derived from RGCs) was measured using the photopic negative response of the photopic ERG and the positive scotopic response of the scotopic full-field ERG. was substantially delayed in 12- and 18-month-old animals, with functional recovery being restored at 28 days (Figure 1). ${ }^{14}$ Histological assessment of retinal cross sections taken up to 28 days post injury revealed only low levels of RGC loss at 28 days (around 10\%), but a substantial reduction in the thickness of the inner plexiform layer. ${ }^{15}$ Loss of inner retinal function was also associated with a reduction in the postsynaptic marker PSD95 in the inner retina and activation of complement factor $\mathrm{C} 1 \mathrm{q}$, which marks damaged synapses for removal by microglia. ${ }^{16}$

We have gone on to show that intermittent fasting and exercise, two interventions that slow biological ageing, improved RGC recovery in older animals, such that exercised 12-month-old animals exhibited full functional recovery by 7 days and so behaved in a similar manner to younger 3 -month-old mice. ${ }^{14,17}$ In the case of exercise, improved recovery occurred even when exercise was initiated $24 \mathrm{~h}$ after IOP injury. The retina of exercised animals also manifest reduced astrocytosis, reduced microglial activation, and reduced C1Q activation following injury, and this was associated with the preservation of synapse density in the inner plexiform layer of the retina.

The neurotrophic factor BDNF is known to protect RGCs $^{18}$ and has previously been shown to be upregulated in regions of the CNS in response to exercise, possibly through the action of $\beta$-hydroxybutyrate on HDAC2 and $3 .{ }^{19}$ We therefore investigated the role of BDNF in improving RGC recovery. Inhibition of the BDNF TrkB receptor completely abrogated the effect of exercise. A similar loss of protection was observed in genetically modified mice with reduced BDNF. ${ }^{15}$ BDNF therefore appears to have an important role in exercise-derived protection. Interestingly, BDNF levels are not increased in the retina in exercised animals, rather a reduction in retinal BDNF levels is observed 7 days post injury in nonexercised 12-month-old animals, whereas BDNF levels are maintained in 12-month-old animals at the same time point when exercised. ${ }^{15}$ The source and mechanisms by which BDNF is maintained in the retina of exercised animals remains to be determined.

The cellular response to injury is depicted in Figure 2 that proposes different responses depending on the level of damage and the capacity of a cell to handle said damage. Clinical and experimental evidence thus points to RGCs maintaining the capacity to recover function following an IOP challenge after periods of function impairment. Functional recovery in the mouse eye appears to be dependent on animal age and can be modified by lifestyle factors such as diet and exercise. Investigating the capacity for RGC recovery in models of long-term IOP elevation will shed further light as to the relevance of this in chronic conditions such as glaucoma. 
Cellular response to injury

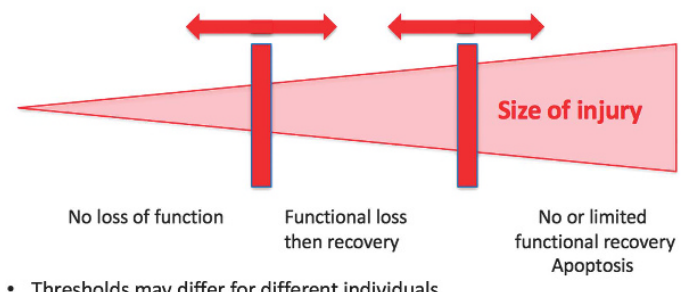

- Thresholds may differ for different individuals

- Thresholds may be modified

Figure 2 The cellular response to injury suggests that, with accumulating levels of injury, a cell will initially continue normal function while undergoing repair. Once a homeostatic threshold is surpassed, the cell stops usual function and focuses its attempts on repair. Once a second threshold is surpassed, the cell is no longer able to repair and initiates a cell death program. These thresholds may vary across cells and between individuals, and are modifiable by interventions.

We postulate that subpopulations of RGCs in glaucoma eyes manifest impaired function as they undergo cycles of injury and repair in response to IOP elevation, and potentially other metabolic and vascular challenges. The proportion of nonfunctioning RGCs may ultimately determine the degree by which the ERG and other parameters of visual function can improve in response to IOP lowering, and may explain the relatively consistent observation that functional recovery is usually greatest in younger patients in the earlier stages of disease.

\section{Conflict of interest}

The authors declare no conflict of interest. The Centre for Eye Research Australia receives indirect grant funding support (OIS) from the Victorian State Government.

\section{References}

1 Ventura LM, Porciatti V. Restoration of retinal ganglion cell function in early glaucoma after intraocular pressure reduction: a pilot study. Ophthalmology 2005; 112: 20-27.

2 Paterson G. Effect of intravenous acetazolamide on relative arcuate scotomas and visual field in glaucoma simplex. Proc $R$ Soc Med 1970; 63: 865-869.

3 Spaeth G. Control of glaucoma: a new definition (editorial). Ophthalmic Surg 1985; 104: 256-264.

4 Katz LJ, Spaeth GL, Cantor LB, Poryzees EM, Steinmann WC. Reversible optic disk cupping and visual field improvement in adults with glaucoma. Am J Ophthalmol 1989; 107: 485-492.

5 Gandolfi SA, Cimino L, Sangermani C, Ungaro N, Mora P, Tardini MG. Improvement of spatial contrast sensitivity threshold after surgical reduction of intraocular pressure in unilateral high-tension glaucoma. Invest Ophthalmol Vis Sci 2005; 46: 197-201.

6 Niyadurupola N, Luu CD, Nguyen DQ, Geddes K, Tan GX, Wong CC et al. Intraocular pressure lowering is associated with an increase in the photopic negative response (PhNR) amplitude in glaucoma and ocular hypertensive eyes. Invest Ophthalmol Vis Sci 2013; 54: 1913-1919.

7 Sehl M, Grewal DS, Goodkin ML, Greenfield DS. Reversal of retinal ganglion cell dysfunction after surgical reduction of intraocular pressure. Ophthalmology 2010; 117: 2329-2336.

8 Waisbourd M, Ahmed OM, Molineaux J, Gonzalez A, Spaeth GL, Katz LJ. Reversible structural and functional changes after intraocular pressure reduction in patients with glaucoma. Graefes Arch Clin Exp Ophthalmol 2016; 254: 1159-1166.

9 Casson RJ, Han G, Ebneter A, Chidlow G, Glihotra J, Newland $\mathrm{H}$ et al. Glucose-induced temporary visual recovery in primary open-angle glaucoma: a double-blind, randomized study. Ophthalmology 2014; 121: 1203-1211.

10 Shibeeb O, Chidlow G, Han G, Wood JP, Casson RJ. Effect of subconjunctival glucose on retinal ganglion cell survival in experimental retinal ischaemia and contrast sensitivity in human glaucoma. Clin Exp Ophthalmol 2016; 44: 24-32.

11 Caprioli J, de Leon JM, Azarbod P, Chen A, Morales E, Nouri-Mahdavi $\mathrm{K}$ et al. Trabeculectomy can improve long-term visual function in glaucoma. Ophthalmology 2016; 123: $117-128$.

12 Kong YX, Crowston JG, Vingrys AJ, Trounce IA, Bui VB. Functional changes in the retina during and after acute intraocular pressure elevation in mice. Invest Ophthalmol Vis Sci 2009; 50: 5732-5740.

13 Crowston JG, Kong YX, Trounce IA, Dang TM, Fahy ET, Bui BV et al. An acute intraocular pressure challenge to assess retinal ganglion cell injury and recovery in the mouse. Exp Eye Res 2015; 141: 3-8.

14 Kong YX, van Bergen N, Bui BV, Chrysostomou V, Vingrys AJ, Trounce IA et al. Impact of aging and diet restriction on retinal function during and after acute intraocular pressure injury. Neurobiol Aging 2012; 33: 1126.e15-25.

15 Chrysostomou V, Galic S, van Wijngaarden P, Trounce IA, Steinberg GR, Crowston JG. Exercise reverses age-related vulnerability of the retina to injury by preventing complement-mediated synapse elimination via a BDNFdependent pathway. Aging Cell 2016; e-pub ahead of print 9 September 2016; doi:10.1111/acel.12512.

16 Stevens B, Allen NJ, Vazquez LE, Howell GR, Christopherson KS, Nouri $\mathrm{N}$ et al. The classical complement cascade mediates CNS synapse elimination. Cell 2007; 131: 1164-1178.

17 Chrysostomou V, Kezic JM, Trounce IA, Crowston JG. Forced exercise protects the aged optic nerve against intraocular pressure injury. Neurobiol Aging 2014; 35: 1722-1725.

18 Martin KR, Quigley HA, Zack DJ, Levkovitch-Verbin H, Kielczewski J, Valenta D et al. Gene therapy with brainderived neurotrophic factor as a protection: retinal ganglion cells in a rat glaucoma model. Invest Ophthalmol Vis Sci 2003; 44: 4357-4365.

19 Sleiman SF, Henry J, Al-Haddad R, El Hayek L, Abou Haidar E, Stringer $\mathrm{T}$ et al. Exercise promotes the expression of brain derived neurotrophic factor (BDNF) through the action of the ketone body beta-hydroxybutyrate. Elife 2016; 5 pii: e15092; doi:10.7554/eLife.15092. 